\title{
Supplemental Instruction Animations to Teach Introductory College Mathematics for Student-Athletes
}

\author{
Kinnis Gosha \\ Assistant Professor, Computer Science, Morehouse College, Atlanta, Georgia, United States of America
}

\begin{abstract}
Research has shown a correlation between student-athletic participation and collegiate academic major selection. Most athletes avoid academic majors in Science, Technology, Engineering and Mathematics (STEM) fields which all require a strong background in Mathematics. This paper introduces Mango - a web-based, multimedia infused software application that offers culturally relevant supplemental math instruction for entry-level college mathematics courses. This application is an attempt to increase the success rate of freshmen student-athletes in mathematics. Additionally, the application aims to lessen the barrier that discourages college athletes from majoring in STEM disciplines.
\end{abstract}

Keywords: STEM, student-athletes, culturally relevant, math instruction, web-based software, application, academic major selection

\section{INTRODUCTION}

All across the country, athletics have been a source of pride, entertainment and unity for many college fans, students and alumni. To protect the interest of the student-athletes who participate in these athletics, most schools join the primary governing body for student-athletes across the country, the National Collegiate Athletic Association (NCAA). The core purpose of the NCAA is to "govern competition in a fair, safe, equitable and sportsmanlike manner, and to integrate intercollegiate athletics into higher education so that the educational experience of the student-athlete is paramount" (About the NCAA, 2011). In 2003, the NCAA adopted rules that focus on improving graduation rates among its scholar-athletes. Athletic departments at various universities take serious measures to keep their athletes in good academic standing to preserve their eligibility to play for the NCAA. With the continuous monitoring of athletes' academic progress, and the pressure that the NCAA places on athletes' academic standing, athletes tend to select majors they perceive to be less demanding in means to maintain their eligibility to play.

According to a poll given by USA Today, eighty-three percent of the participating colleges had at least one cluster of student-athletes in the same major program (Upton \& Novak, 2008). Additionally, one-third of schools had two or more teams clustering in the same major program (Upton \& Novak, 2008). Clustering occurs when $25 \%$ or more of an athletic team shares a single academic major (Fountain \& Finle, 2009, p. 1).

A 2008 research study addressing clustering was conducted with 120 Football Bowl Subdivision (formerly Division IA) schools and 22 Division I schools (Upton, Steeg, Bohn, \& Berkowitz, 2008). Results from the study suggest that most athletes participating in popular sports such as football, baseball, softball, and men's and women's basketball tend to cluster around majors such as social science, communication, and business (see Figure 1).

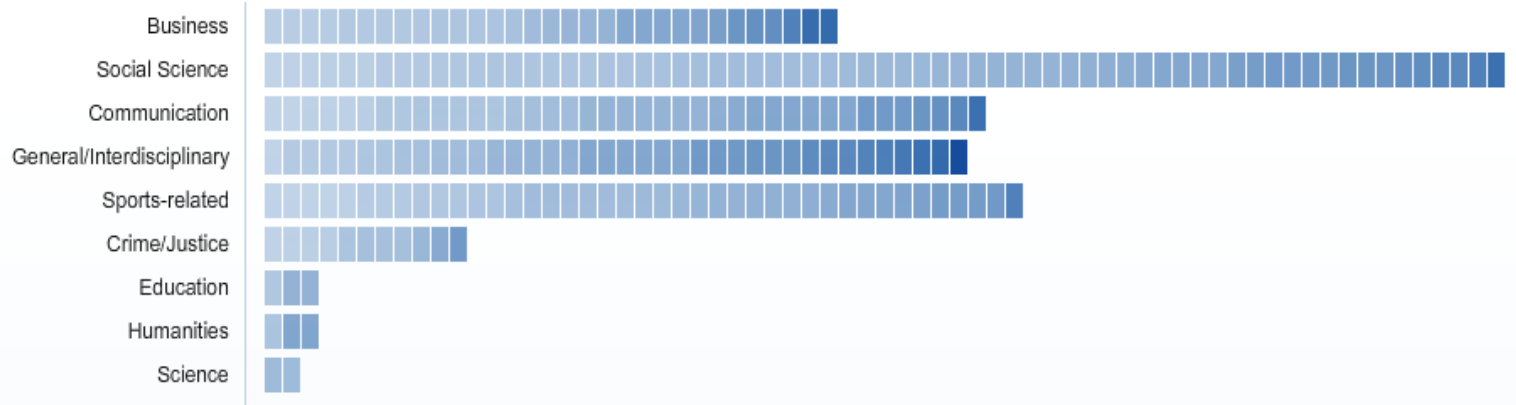

Figure 1: Academic major clustering 
It is probable that athletes choose their majors according to rigor, rather than where their specific academic interest lie. Some athletes say that they have been steered towards certain majors to ensure eligibility to play sports. When interviewed, former Boise State Football player Marty Tadman expressed in an interview, "You hear which majors, and which classes, are the easiest and you take them... you're going to school so you can stay in sports. You're not going for a degree...It's a joke" (Upton, Steeg, Bohn, \& Berkowitz, 2008). Participation on a sport team is a serious matter for many athletes. For those who participate in the two traditionally revenue producing sports, Football and Men's Basketball, athletics are even more significant since many of them are "auditioning" to be drafted into the professional basketball or football leagues. As a result, seeking a less demanding major is a popular choice.

While some studies have investigated major clustering among student-athletes, no research has been published that shows reasons why athletes shy away from STEM majors. STEM majors are considered more demanding by many since they acquire a strong mathematics background. New incoming college students that lack a solid background in math and science are at a disadvantage in entering STEM majors (Government Accountability Office 2005). An attempt to alleviate this barrier for student-athletes is a project entitled "Mango". Section two will discuss the concept behind the Mango project. In section three, the technical requirements for the tool's construction will be addressed. Section four and five will highlight the team and skillsets needed to development Mango as well as the development process for the content of the tool. How the project was managed is reviewed in section six. The pilot study results and future work are presented in sections seven and eight.

\section{CONCEPT}

Project Mango is a web-based, multimedia infused software application that offers supplemental math instruction in an innovative way. The application uses culturally relevant cues such as hip-hop music, familiar athletes and sport themes to teach entry level college mathematics. Entry level mathematics was chosen as the initial target area because of the impact it has as a prerequisite for other STEM courses. In addition, educators are dealing with mathematics curriculum reform in order to make mathematics more relevant and meaningful for students, to encourage students to think critically, and to make the process of learning mathematics more student-centered and interactive (Faggiano, Pertichino \& Roselli, 2005).

Mango uses familiar names, landmarks and sport themes from a variety of sports across a college campus. These familiarities are embedded in multimedia animations created with Adobe Flash. These animations, or lessons, are combined with hip-hop music and housed in a web-accessible interface. This format in which the application was created allows for users to access its contents from their mobile devices, in addition to their computers.

Once a user logs into the Mango system, they have the option to select a course in addition to a lesson in that course. When a lesson is selected, the lesson automatically starts to play. After the animation is complete, the user has the option to replay the animation, return the previous animation, go to the next sequential animation or return back to the main menu (See figures 2.1, 2.2 and 2.3).
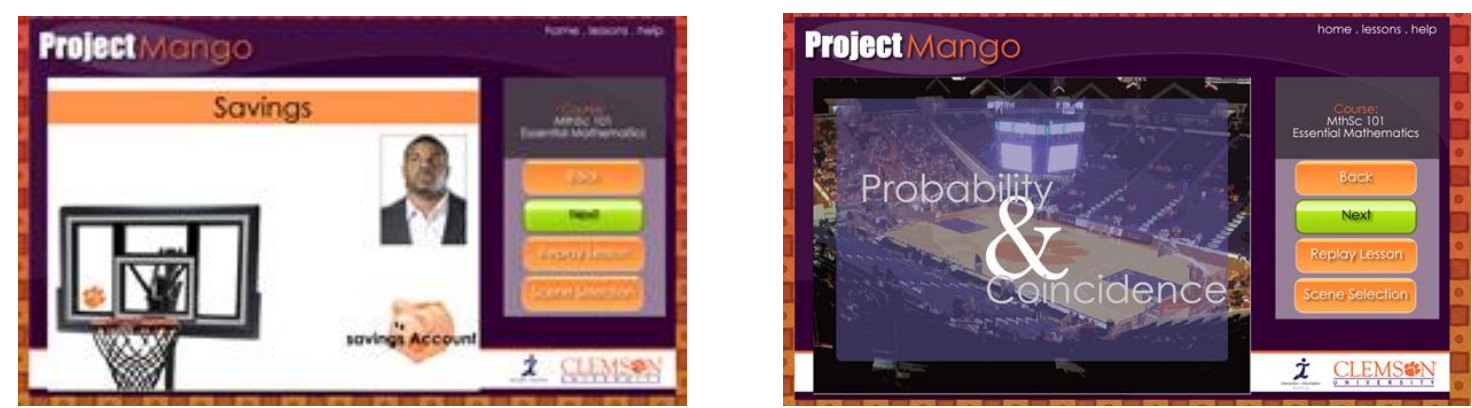

Figure 2.1: Screenshot of Project Mango interface Figure 2.2: Screenshot of Project Mango interface

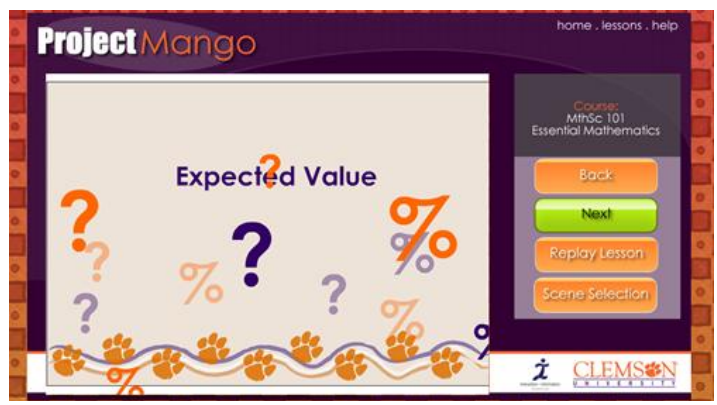

Figure 2.3: Screenshot of a Project Mango lesson 
Vol. 6, Issue 6, June 2017

\title{
III. PROJECT DEVELOPMENT
}

\begin{abstract}
A. Selected Course
The first iteration of Project Mango targeted the Essential Mathematics course at a major Research I university. This course was selected because it is a required course that is taken by most freshman students at that school, including student-athletes. Course instructors identified two chapters in the textbook that previously gave students the most difficulty: Probability and Financial Mathematics. After a thorough review of the course text, 42 different key concepts where chosen from the two chapters (28 from Financial Mathematics \& 14 from Probability).
\end{abstract}

\section{B. Development Team}

The team selected to work on the development of the tool was comprised of six students: two doctoral students majoring in Human Centered Computing, two undergraduates majoring in Computer Science and two undergraduates majoring in Art. Because of the large quantity of lessons that had to be completed, it was pivotal that the work was allocated equally amongst the team members. It was also important that team members were assigned tasked that aligned with their strengths.

One graduate student member was assigned the role of team leader and managed the distribution of task and the website design. The other graduate student member was charged with the supervising the undergraduates, music selection and training them on how to use the animation software. One undergraduate student (residing at another institution two hours away) was responsible for the lesson creation and voice recording. The last three undergraduates (including the two Art majors) were responsible for the animating of all the lessons.

\section{Animation Development Process}

It took three months before a standard development process could be created. The final process consisted of five phases for creating and implementing each Mango lesson: 1) Script Creation, 2) Voice Recording, 3) Flash Development, 4) Software Integration, and 5) Lesson Effectiveness. When a lesson has been assigned, the team meets to review the material and agree upon an outline of important key points relating to the material at hand. Once the material has been reviewed, it is then given to the script writer where the material is translated into a script. The process of developing the script consists of finding a sport, then translating the mathematical material into story using examples from that sport. Once the script is complete, it is then sent out for approval. By that, the first phase is complete.

Next, the script is ready to be broken up into segments of sentences for voice recording purposes. The team member responsible for recording the audio also points out keywords in the broken segments that need emphasized. Emphasizing certain words in the audio recording gives the word notation of importance that will later help the animators with their part of the process. Once a script is transformed into audio, it is then distributed to the animators to start the next phase.

When animators receive the recordings, they first have to review them thoroughly to make sure that 1) the recordings match the script submitted, and 2) the audio meets certain conditions, such as a certain speed and length and audio pauses, for animation purposes. They then go forth with creating a storyboard. In a storyboard, the animator has to illustrate the words in the script with graphics. Animators should also develop a good understanding of the sport used in the lesson. Keeping in mind the attributes of the audio recordings and the nature of the lesson, the animators choose a suitable piece of background music and gather any other necessary elements to complete their animation. For example, each script names an athlete and uses him or her for illustration purposes. The animator has to gather pictures of the athlete and the sport itself to help bring forth the examples used in the script. At the end of each lesson, the animator is responsible for creating a summary slide with the key points of the lesson. Using Adobe Flash, the animators create and publish the animation for the lesson then they send it out for review. When all goes well, the next phase of the process is to take these animations and upload it to the server updating the project directory. The lesson is then linked to a live webpage where the published animation file is embedded and tested.

The final phase of the process is to test for lesson effectiveness. After completing a lesson, a team member develops a short quiz of multiple choice questions that closely relate to the content of the lesson demonstrated in the animation. The effectiveness of a lesson is and measured by how well a student performs on the quizzes that follow the lessons. After quizzes are submitted online, they are automatically checked and the results are preserved for further analysis.

\section{PILOT STUDY}

A pilot study was conducted consisting of eight participants once the first version of Mango was released. The goals of the study was to collect some preliminary data about student-athletes' attitude towards Project Mango and to test the reliability of the survey questions that would be included in the first major study to occur later on that year. Of those 
students who participated in the study, six were student-athletes and two were tutors. The gender of the student athletes included four females and two males. Sports played by the students athletes included three track \& field players, two volleyball players and one soccer player. The participants were given a survey instrument that included eight statements. Responses were measured using a 5-level likert scale (1. Strongly Disagree, 2. Disagree, 3. Undecided, 4. Agree, and 5. Strongly Agree).

In statistics, reliability is the consistency of a set of measurements or of a measuring instrument, often used to describe a test (Meeker \& Escobar, 1998). We used SPSS; a statical software used for survey authoring and deployment, data mining, text analytics, statistical analysis, and collaboration and deployment, in order to confirm reliability of the survey statements. We also used Cronbach's Alpha Coefficient, a measure of the internal consistency or reliability of a psychometric test score for a sample of examinees (Cronbach, 1951), to test reliability of the survey.

\section{RESULTS}

The pilot studies produced positive results. First, when students were asked if "learning with Mango was more interesting than learning in class", all participants agreed. Second, all participants also agreed that "The way the lesson was taught made me more interested in the topic". When asked to rate "I wish all my math lessons could have a module in Project Mango" all participants agreed as well. Participants where also asked "If these lessons where available to me, I would use them in my class" and "The lesson I viewed was easy to understand". These statements were rated either "Agree" or "Strongly Agreed" by all but one participant.
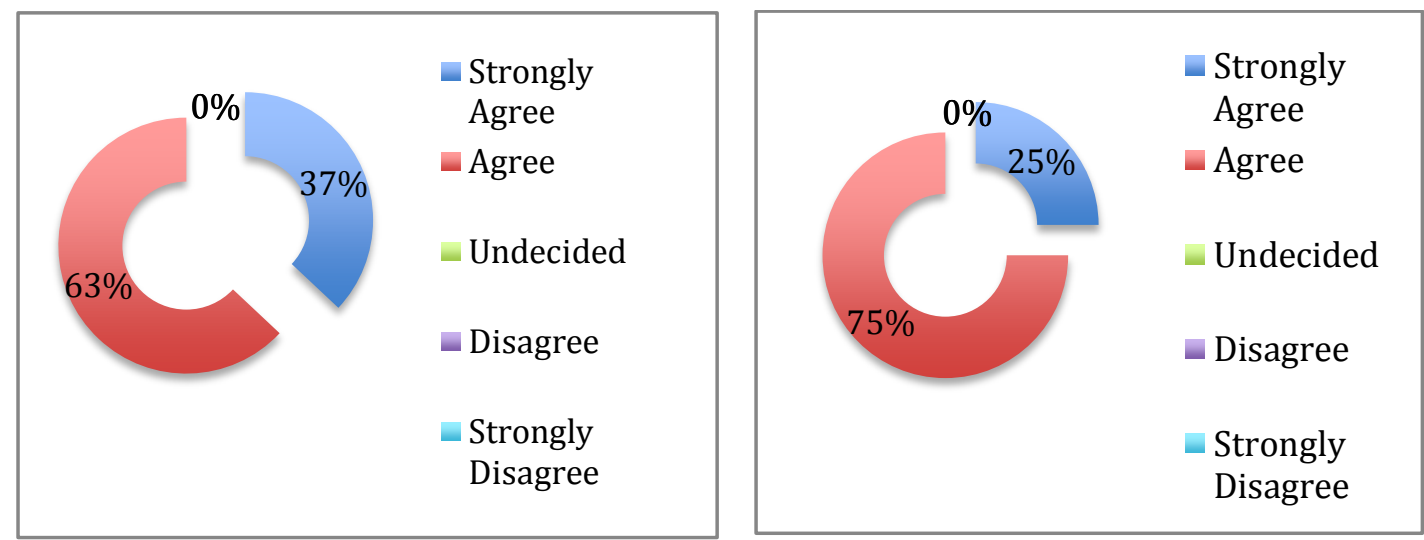

Figure 7.1: Learning with Mango is more interesting than learning in class Figure 7.2: The way the lesson was taught made me more interested in the topic
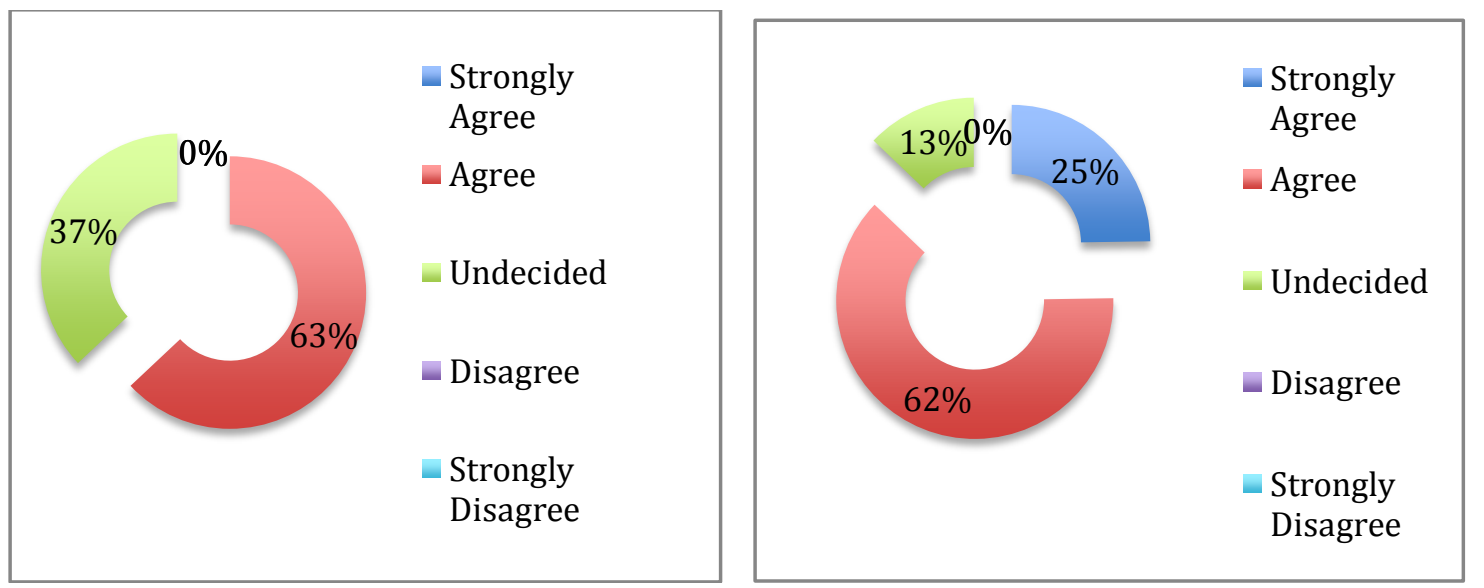

Figure 7.3: I wish all my math lessons could have a module in Project Mango Figure 7.4: If these lessons where available to me, I would use them in my class

\section{FUTURE WORK}

Overall, results of the pilot study look promising for the Mango tool. As a result, further studies will be conducted where the survey instrument will be administered to a larger population of student-athletes across multiple 
universities. In these studies, the athletic academic representative will inform students-athletes about the application and the research study that is associated with it. From there, they will have the choice to participate in the study or not. The Mango research team will implement the study by integrating the application in the curriculum for different chapters of the course. After those chapters of the course are completed, students will be asked to provide qualitative as well as quantitative feedback on their learning experience using the tool. In addition, data will be collected to compare the quiz results from those student athletes who used Mango to those student athletes that did not use Mango. We expect the athletes who used Mango will perform somewhat better overall than the athletes that decided not to use the tool.

\section{REFERENCES}

[1] About the NCAA. (2011). Retrieved March 8, 2011, fromhttp://www.ncaa.org/wps/wcm/connect/public/ncaa/about+the+ncaa

[2] Cronbach, L. (1951). Coefficient alpha and the internal structure of tests. Psychometrika, 16(3), 297-334.

[3] Faggiano, E., Pertichino, M., \& Roselli, T. (2005). CSCL in Math Education. Frontiers in Education, 2005. FIE '05. Proceedings 35th Annual Conference, 35, F4C - F4C

[4] Fountain, J., \& Finle, P. (2009). Academic Majors of Upperclassmen Football Players in the Atlantic Coast Conference: An Analysis of Academic Clustering Comparing White and Minority Players. Journal of Issues In Intercollegiate Athletics, 2, 1-13.

[5] Government Accountability Office (2005). Higher education: Federal science, technology, engineering, and mathematics programs and related trends. Report to the Chairman, Committee on Rules, House of Representatives, GAO-06-114.

[6] Meeker, W. Q., \& Escobar, L. A. (1998). Statistical methods for reliability data. New York: Wiley.

[7] Renick, J. (1974). The use and misuse of college athletics. The Journal of Higher Education, 45(7), 545-552.

[8] Upton, J., \& Novak, K. (2008). College athletes cluster majors at most schools - USATODAY.com. News, Travel, Weather, Entertainment, Sports, Technology, U.S. \& World - USATODAY.com. Retrieved March 12, 2011, from http://www.usatoday.com/sports/college/2008-11-18majors-graphic_N.htm

[9] Upton, J., Steeg, J., Bohn, P., \& Berkowitz, S. (2008). College athletes studies guided toward 'major in eligibility' -USATODAY.com. News, Travel, Weather, Entertainment, Sports, Technology, U.S. \& World - USATODAY.com. Retrieved March 10, 2011, from http://www.usatoday.com/sports/college/2008-11-18-majors-cover_N.htm 